'Grupo de Investigación en Farmacoepidemiología y Farmacovigilancia, Universidad Tecnológica de Pereira Audifarma S.A. Pereira, Colombia.

${ }^{2}$ Fundación Universitaria Autónoma de las Américas. Pereira, Colombia.

${ }^{\mathrm{a}} \mathrm{MD}$. ${ }^{\mathrm{b} P h D}$. "MSc.

Sources of funding: The study received funding from Tecnoquímicas S.A. Tecnoquímicas did not participate in the study design or execution or in the collection, management, analysis or interpretation of the data.

Recibido el 30 de diciembre de 2019, aceptado el 26 de mayo de 2020 .

Correspondence:

Jorge Enrique Machado-Alba Grupo de Investigación en Farmacoepidemiología y Farmacovigilancia. Universidad Tecnológica de Pereira-Audifarma S.A, Address: Calle 105 No. 14140, Pereira, Risaralda, Colombia,

Zip Code: 660003. machado@utp.edu.co memachado@utp.edu.co

\section{Adherence to levothyroxine prescription in patients with hypothyroidism}

\author{
JORGE E. MACHADO-ALBA ${ }^{1, a, b, c}$, MANUEL E. MACHADO-DUQUE
}

\begin{abstract}
Background: Hypothyroidism occurs in 1-2\% of the general population, is associated with significant morbidity and requires continuous treatment with levothyroxine. Aim: To determine the effectiveness, adherence and safety of levothyroxine therapy in patients with hypothyroidism. Material and Methods: The Morisky-Green adherence test was applied, and effectiveness was determined by measuring thyroid-stimulating hormone (TSH) in 330 patients with with hypothyroidism; the mean age was $64+-15$ years and $76 \%$ was women. Results: Median TSH was 2.09 mIU/L (interquartile range: 1.16-3.61 mIU/L). Two hundred thirty-five (71\%) patients had TSH levels in the euthyroid range, $64(19 \%)$ in the hypothyroid range and 31 (9\%) in the hyperthyroid range. Complete, moderate and lack of adherence with levothyroxine was reported in 283 (86\%), 29 (9\%) and 18 (5\%) of patients, respectively. The presence of anemia (odds ratio (OR): 0.37, 95\% confidence intervals (CI): 0.15-0.98) or the need of doses over $100 \mu \mathrm{g} /$ day (OR: 0.47, 95\%CI: 0.28-0.80) increased the probability of having an abnormal TSH level. Conclusions: In a large proportion of these patients, TSH levels were controlled, and most patients were adherent to levothyroxine therapy.
\end{abstract}

(Rev Med Chile 2020; 148: 740-745)

Key words: Hypothyroidism; Pharmacoepidemiology; Thyroxine;Treatment Adherence and Compliance.

\section{Adherencia al uso de levotiroxina en pacientes con hipotiroidismo}

Antecedentes: El hipotiroidismo se presenta entre el 1-2\% de la población general, genera importante morbilidad y requiere tratamiento con levotiroxina de manera continua. Objetivo: Determinar la efectividad, adherencia y seguridad de la terapia con levotiroxina en pacientes con hipotiroidismo. Materialy Métodos: Se aplicó test de adherencia de Morisky-Green y se determinó efectividad mediante medición de TSH en 330 pacientes con edad promedio $63 \pm 15$ años (76\% mujeres). Resultados: La mediana de TSH fue 2,09 mUI/l, (rango intercuartílico: 1,16mUI/l-3,61 mUI/l). Un total de 235 (71,2\%) tenían cifras de TSH en rango de estado eutiroideo, $64(19,4 \%)$ se catalogaron hipotiroideos $y 31$ (9,4\%) hipertiroideos. El 86\% $(n=283)$ manifestó tener adherencia completa al medicamento, 29 (9\%) moderada y 18 (5\%) se clasificaron poco adherentes. Tener diagnóstico de anemia (razón de riesgo (RR): 0,37; intervalos de con- 
fianza (IC) 95\%: 0,15-0,98) o necesitar dosis mayores de 100 нg/día (RR: 0,47; IC95\%: 0,28-0,80) elevaron la probabilidad de no controlar el hipotiroidismo. Conclusiones. Una alta proporción de pacientes se encuentran controlados y con mucha frecuencia son adherentes a la terapia con levotiroxina.

Palabras clave: Cumplimiento y Adherencia al Tratamiento; Farmacoepidemiología; Hipotiroidismo; Tiroxina.

T Thyroid hormone (levothyroxine) replacement therapy, because of its excellent effectiveness and safety, is indicated as a continuous treatment when a diagnosis of hypothyroidism is confirmed ${ }^{1}$; levothyroxine is one of the most commonly prescribed drugs in the world and the second most frequently consumed drug in the United States of America ${ }^{1}$. In Colombia, previous prescription studies showed that it is a widely used drug, mainly by women $(80 \%$ of the population) approximately 60 years of age. It is estimated that the global prevalence of hypothyroidism is $1 \%$ to $2 \%$ in the general population ${ }^{1-3}$.

In Colombia, hypothyroid patients are managed with a variety of forms of levothyroxine and are periodically monitored to ensure maintenance of TSH levels in the euthyroid range (TSH between 0.4 and $4 \mathrm{mIU} / \mathrm{L}$ ), with the aim of improving their symptoms and reducing possible complications. However, epidemiological studies have shown that only between 40 and $60 \%$ of those affected are within the control range established for their pathology $y^{4,5}$.

Given that hypothyroidism is a common disease and its only management consists of thyroid hormone replacement therapy, it is of interest to obtain data on its treatment, generating tools that enable better decisions that benefit the patient and the health system. Therefore, the objective was to determine the effectiveness of, adherence to and safety of levothyroxine therapy in a sample of patients diagnosed with hypothyroidism in the city of Medellín, Colombia, from 2016 to 2017.

\section{Materials and Methods}

An observational follow-up study was performed in a cohort of patients diagnosed with hypothyroidism under continuous management with levothyroxine in any of the different presentations, over 18 years of age, of any gender, who were residents in the metropolitan area of the city of Medellín, Colombia, between August 1, 2016, and June 30,2017, and who were cared for at the IPS Universitaria-Universidad de Antioquia.

A simple random sample of all the patients in treatment at the institution was obtained, with an error of 5\%, a confidence level of $95 \%$ and an expected control of $50 \%$, which corresponded to 330 subjects. The variables of interest in the clinical histories were obtained. Additionally, information on adherence to the therapy was obtained through a personal interview that was conducted by the attending physician, and TSH samples were obtained by duly qualified laboratory personnel after each of the patients signed an informed consent form.

The following variables were collected and entered into a database:

1. Sociodemographic: age, gender, urban or rural origin.

2. Clinical: reported symptoms of hypothyroidism in the clinical history, number of consultations during the year of follow-up, and serum TSH values before and during the study period. The serum TSH test was performed in the IPS Universitaria laboratory using standardized methodology. The same technique was used for all patients.

3. Pharmacological: levothyroxine doses and pharmaceutical presentation.

4. Comorbidities: 1) hypertension; 2) dyslipidemia; 3 ) ischemic heart disease; 4) cerebrovascular disease; 5) diabetes mellitus; 6) osteoporosis; 7) anemia; 8) gastroesophageal reflux; 9) depression; and 10) other comorbidities considered of clinical importance in this population.

5. Safety: adverse reactions associated with levothyroxine and reported in the patient's medical history.

6. Adherence: Adherence was assessed by interviewing each patient with the 4-point Moris- 
ky-Green test. Patients were classified as highly adherent if all responses were negative, moderately adherent if they had a positive response and non-adherent if they had more than one positive response.

The effectiveness was defined according to the TSH value obtained in the test performed by the authors during the study period. Values between 0.4 and $4 \mathrm{mIU} / \mathrm{L}$ were classified as euthyroidism, values less than $0.4 \mathrm{mIU} / \mathrm{L}$ were classified as hyperthyroidism, and values greater than $4 \mathrm{mIU} / \mathrm{L}$ were classified as hypothyroidism.

This study was endorsed by the Bioethics Committee of the Universidad Tecnológica de Pereira under the category "research with minimal risk". Personal data of the study subjects were not considered, and the ethical principles established by the Declaration of Helsinki were respected.

\section{Data analysis}

The data were analyzed with the statistical package SPSS Statistics version 25.0 for Windows (IBM Corp. 2017, Armonk, NY. USA). Frequencies, proportions and measures of central tendency were established (mean, standard deviation, median and interquartile ranges). The $\chi^{2}$ test was used to compare categorical variables. For logistic regression, the dependent variable was the control of hypothyroidism (yes/no) based on the TSH result, and the independent variables were the variables with levels of statistical significance in the bivariate analyses of each group. A value of $\mathrm{p}<0.05$ indicated statistical significance.

\section{Results}

A total of 330 patients with hypothyroidism treated with levothyroxine, with an mean age of $62.9 \pm 15.1$ years were included; the patients were predominantly female $(\mathrm{n}=251 ; 76.1 \%)$. The vast majority of patients were of urban origin $(n=297 ; 90 \%)$. The symptoms reported most frequently were drowsiness and fatigue, and the most common comorbidities present in the research subjects were dyslipidemia and arterial hypertension (table 1 ).

From the TSH results obtained after standardized measurement, a total of 235 (71.2\%) patients had TSH levels that placed them in the euthyroid range, while, $64(19.4 \%)$ were classified as hypothyroid and the remaining 31 (9.4\%) were classified as hyperthyroid (Table 2). The median TSH of all the patients treated with levothyroxine was $2.09 \mathrm{mIU} / \mathrm{L}$, (interquartile range: 1.16 $\mathrm{mIU} / \mathrm{L}-3.61 \mathrm{mIU} / \mathrm{L}$ ), with a minimum value of $0.01 \mathrm{mIU} / \mathrm{L}$ and maximum value of $76.8 \mathrm{mIU} / \mathrm{L}$.

Regarding the assessment of follow-up care in the last year, there were $117(35.5 \%)$ patients who had two follow-up consultations, followed by $111(33.6 \%)$ who visited four times, 50 (15.2\%) who had three consultations, $24(7.3 \%)$ who had a single consultation and the remaining $28(8.4 \%)$ who visited at different frequencies throughout the year.

A low frequency of adverse reactions was reported by the patients, with only eight $(2.4 \%)$ individuals presenting any complaint in this regard. Epigastralgia was the most frequent adverse reaction (three cases, $0.9 \%$ ), followed by headache (two cases, $0.6 \%$ ), and the remaining patients experienced heart palpitations, dry mouth and tremor.

\section{Table 1. Symptoms and comorbidities more frequent in 330 patients diagnosed with hypothyroidism in treatment with levothyroxine}

\begin{tabular}{|lrr|}
\hline Characteristics & n & \% \\
Symptoms & & \\
Paresthesias and carpal tunnel syndrome & 148 & 44.8 \\
Somnolence & 134 & 40.6 \\
Fatigue & 131 & 39.7 \\
Hair loss & 128 & 38.8 \\
Cold intolerance & 124 & 37.6 \\
Constipation & 118 & 35.8 \\
Anorexy & 61 & 18.5 \\
Menstrual disorders (n: 201) & 20 & 9.9 \\
Comorbidities & & \\
Dyslipidemia & 170 & 51.5 \\
Arterial hypertension & 162 & 49.1 \\
Gastroesophageal reflux & 80 & 24.2 \\
Depression & 77 & 23.3 \\
Diabetes mellitus & 57 & 17.3 \\
Anxiety disorders & 44 & 13.3 \\
Osteoporosis & 41 & 12.4 \\
Coronary heart disease & 37 & 11.2 \\
Anemia & 23 & 7.0 \\
Cancer & 16 & 4.8 \\
\hline
\end{tabular}


Table 2. Treatment effectiveness of 330 patients diagnosed with hypothyroidism treated with levothyroxine according to the dose delivered

\begin{tabular}{|lcccccccc|}
\hline Dose & $\begin{array}{c}\text { Total patients } \\
(\mathbf{n}=\mathbf{3 3 0})\end{array}$ & $\begin{array}{c}\text { Euthyroid } \\
\text { (n) }\end{array}$ & $\begin{array}{c}\text { (\%) } \\
\text { Hypothyroid }\end{array}$ & $\begin{array}{c}\text { (\%) } \\
\text { (n) }\end{array}$ & $\begin{array}{c}\text { Hyperthyroid } \\
\text { (n) }\end{array}$ & $\begin{array}{c}\text { (\%) } \\
\text { Median } \\
\text { TSHa }\end{array}$ \\
\hline $50 \mu \mathrm{g} / \mathrm{day}$ & 116 & 83 & $71.6 \%$ & 29 & $25 \%$ & 4 & $3.4 \%$ & 2.4 \\
\hline $100 \mu \mathrm{g} / \mathrm{day}$ & 69 & 45 & $65.2 \%$ & 14 & $20 \%$ & 10 & $14.5 \%$ & 1.5 \\
$\geq 100 \mu \mathrm{g} /$ day & 99 & 60 & $60.6 \%$ & 20 & $20 \%$ & 19 & $19.2 \%$ & 1.4 \\
$<100 \mu \mathrm{g} /$ day & 231 & 175 & $75.8 \%$ & 44 & $19 \%$ & 12 & $5.2 \%$ & 2.3 \\
\hline
\end{tabular}

Thyroid Stimulating Hormone.

The Morisky-Green adherence test was given to all patients receiving levothyroxine therapy, and it showed that $85.8 \%(n=283)$ of the patients showed complete adherence to the medication. Among the remaining patients, 29 (8.8\%) showed moderate adherence and 18 (5.4\%) were classified as non-adherent.

Initially, bivariate analyses were performed to identify possible variables associated with the lack of hypothyroidism control, serving as the dependent variable. The multivariate analysis adjusted by gender and age showed that having a diagnosis of anemia ( $\mathrm{p}=0.028$; OR: 0.3 ; 95\%CI: $0.15-0.98)$ or needing doses higher than $100 \mu \mathrm{g} /$ day ( $\mathrm{p}=0.005$; OR: 0.47; 95\%CI: 0.280.80 ) significantly increased the probability of having uncontrolled hypothyroidism by $63 \%$ and $53 \%$, respectively.

\section{Discussion}

We showed the effectiveness of and adherence to thyroid hormone replacement therapy in a Colombian population based on TSH values for each patient, a method that provides a high level of certainty and reliability of the results presented. Additionally, each patient was assessed to determine their comorbidities and adverse reactions to levothyroxine therapy.

The sociodemographic characteristics in this sample of patients from the city of Medellín were as expected based on the epidemiology of hypothyroidism, as well as the management with levothyroxine for patients with this disease ${ }^{6}$. For example, a study conducted in Colombia regarding the use of thyroid hormone around the country found almost the same proportion of females $(79.1 \%$ vs $76.1 \%$ current study) and mean population age (63.2 years vs 62.9 years, respectively) ${ }^{2}$.

Most of the comorbidities of the patients evaluated are related to the cardiovascular system, such as dyslipidemia and arterial hypertension, which treating physicians should be aware of due to the risk generated by these pathologies, as well as the growing evidence that shows hypothyroidism as an additional cardiovascular risk factor ${ }^{7,8}$. Other comorbidities found, such as depression, have also been found more frequently in patients with hypothyroidism, which can provide even more information on the current knowledge of hypothyroidism ${ }^{9}$.

Among the patients with hypothyroidism treated with levothyroxine in this sample, a high proportion had TSH values within the recommended range of control, and both the median and interquartile ranges remained within the levels that have been established to ensure adequate management of the pathology ${ }^{4}$. In addition, these values were higher than those reported by Somwaru et al. in the United States of America in 2009 in patients older than 65 years, where only $43 \%$ were in the euthyroid range ${ }^{10}$. Other studies, such as that by Solter et al. in Croatia in 2013, found that $68 \%$ of patients were in the euthyroid range, a value very close to that found in this sample of Colombian patients $^{11}$, and Diez et al. in Spain in 2002 found that therapy was effective in $67.5 \%$ of patients ${ }^{12}$. These slight variations in the results can be explained by the different populations in the studies, with different levels of adherence and education and who were cared for within the different health models of each country, all of which can influence treatment effectiveness. 
A high adherence to therapy was found in the majority of patients, which is an important outcome because chronic pathologies, such as hypertension, diabetes mellitus and hypothyroidism, are generally associated with poor daily medication compliance. This result highlights the requirements of a good level of commitment and knowledge of the disease, as well as the need for hormone replacement with levothyroxine, to achieve adequate symptom control, which is in accordance with reports from countries such as Spain and India, which also have adherence rates close to $90 \%{ }^{13,14}$.

It is also clear the importance of the physician-patient relationship and the education that the physician can provide together with the health team in order to improve adherence to therapies for chronic pathologies and guarantee better health outcomes. The physician-patient relationship may be influenced by the doctor's interest in the consultation, in part by the doctor's satisfaction with his or her job and workplace, as well as by the patient's compliance with follow-up. It is necessary to have a better understanding of the reasons why in some diseases there may be a better doctor-patient relationship and why this leads to better adherence ${ }^{15}$.

This study shows some limitations of an observational study, namely, the identification of patients from a single city in the country, treatment provided by the same health service provider, and reliance on a single variable (TSH) to define the control status of each case. However, some strengths are present, such as the sample size, the standardized and uniform technique of measuring TSH levels in all subjects, and the measurement of adherence by a trained physician.

\section{Conclusions}

With the results obtained, it can be concluded that a high proportion of the hypothyroidism patient sample have TSH levels in the euthyroid range and are most often adherent to levothyroxine therapy; in addition, few adverse reactions occurred. These data generate confidence in the quality of care and the medicines they are receiving. This study provides information on the adherence to and effectiveness of hypothyroidism therapy and is one of the few studies in the literature that has addressed this issue, particularly in a middle-income country such as Colombia.

\section{Acknowledgments: not applicable.}

Conflict of interests: Tecnoquímicas did not participate in the study design or execution or in the collection, management, analysis or interpretation of the data. The authors express that they have no additional conflicts of interest.

\section{References}

1. Biondi B, Wartofsky L. Treatment with thyroid hormone. Endocrine Rev 2014; 35: 433-512.

2. Machado-Alba J, Valencia-Marulanda J, Jiménez-Canizales C, Salazar V, Romero D. [Thyroid hormone prescription patterns in a Colombian population]. Rev Panam Salud Publica 2014; 36: 80-6.

3. Nash DB. The Use of Medicines in the United States: A Detailed Review. Am Health Drug Benefits 2012; 5: 423.

4. Hennessey JV. Generic vs name brand L-thyroxine products: interchangeable or still not? J Clin Endocrinol Metab 2013; 98: 511-4.

5. Okosieme O, Gilbert J, Abraham P, Boelaert K, Dayan $\mathrm{C}$, Gurnell M, et al. Management of primary hypothyroidism: statement by the British Thyroid Association Executive Committee. Clin Endocrinol 2016; 84: 799-808.

6. Chaker L, Bianco AC, Jonklaas J, Peeters RP. Hypothyroidism. Lancet 2017; 390: 1550-62.

7. Delitala AP, Fanciulli G, Maioli M, Delitala G. Subclinical hypothyroidism, lipid metabolism and cardiovascular disease. Eur J Inter Med 2017; 38: 17-24.

8. Hassan A, Altamirano-Ufion A, Zulfiqar B, Boddu P. Sub-Clinical Hypothyroidism and Its Association With Increased Cardiovascular Mortality: Call for Action. Cardiol Res 2017; 8 (2): 31-5.

9. Dayan CM, Panicker V. Hypothyroidism and depression. Eur Thyroid J 2013; 2 (3): 168-79.

10. Somwaru LL, Arnold AM, Joshi N, Fried LP, Cappola AR. High frequency of and factors associated with thyroid hormone over-replacement and under-replacement in men and women aged 65 and over. J Clin Endocrinol Metab 2009; 94 (4): 1342-5.

11. Solter D, Solter M. Do we treat hypothyroidism properly? A survey of 2488 patients from University Hospital Center, Zagreb, Croatia. Ann Endocrinol 2013; 74 (1): 27-9. 
12. Diez JJ. Hypothyroidism in patients older than 55 years: an analysis of the etiology and assessment of the effectiveness of therapy. J Gerontol A Biol Sci Med Sci 2002; 57 (5): M315-20.

13. Kumar P, Khandelwal D, Mittal S, Dutta D, Kalra S, Katiyar P, et al. Knowledge, Awareness, Practices and Adherence to Treatment of Patients with Primary Hypothyroidism in Delhi. Indian J Endocrinol Metab 2017;
21 (3): 429-33.

14. Mingorance Mingorance MC, García-Jiménez E. [Adherence and knowledge of treatment in hypothyroid patients from a community pharmacy in Seville: a pilot study]. Aten Primaria 2012; 44 (9): 563-5.

15. Seabury SA, Dougherty JS, Sullivan J. Medication adherence as a measure of the quality of care provided by physicians. Am J Manag Care 2019; 25 (2): 78-83. 